


\title{
Entrevista com Fernando Henrique Cardoso: reflexões sobre a educação superior nacional e mundial
}

\author{
Interview with Fernando Henrique Cardoso: \\ reflections about national and world higher education \\ Entrevista con Fernando Henrique Cardoso: \\ reflexiones sobre la educación superior nacional y mundial
}

EVERALDO DA SILVA*

$\diamond$

\begin{abstract}
APRESENTAÇÃo
Intelectual renomado, autor de obras significativas no campo da sociologia, político experiente, Fernando Henrique Cardoso revela nesta entrevista a compreensão acurada da questão da educação superior. Compreensão essa angariada no cotidiano da carreira de professor e pesquisador, na vivência das políticas públicas e no exercício da presidência da Republica.

A biografia auxilia a evidenciar os pontos de referência de sua trajetória, sempre articulando o exercício do pensamento com a prática política. Carioca, nascido em 18 de junho de 1931, é sociólogo formado pela Universidade de São Paulo (USP). Nessa mesma Universidade foi professor, pesquisador e reconhecido com o título de Professor Emérito. Fez carreira internacional, lecionando nas Universidades de Santiago, no Chile; da Califórnia (Stanford e Berkeley), nos Estados Unidos; de Cambridge, na Inglaterra; de Paris-Nanterre, na École des Hautes Études em Sciences Sociales, e no Collège de France, na França. De 2003 a 2007, também foi professor at-large do Thomas J. Watson Jr. Institute for International Studies, da Brown University, nos Estados Unidos.

Recebeu o título de Doutor Honoris Causa de mais de 20 universidades e é membro honorário estrangeiro da American Academy of Artsand Sciences. Além dessas homenagens, foi distinguido com numerosas condecorações, destacando-se o Prêmio John W. Kluge para o estudo da humanidade, concedido em 10/07/2012
\end{abstract}

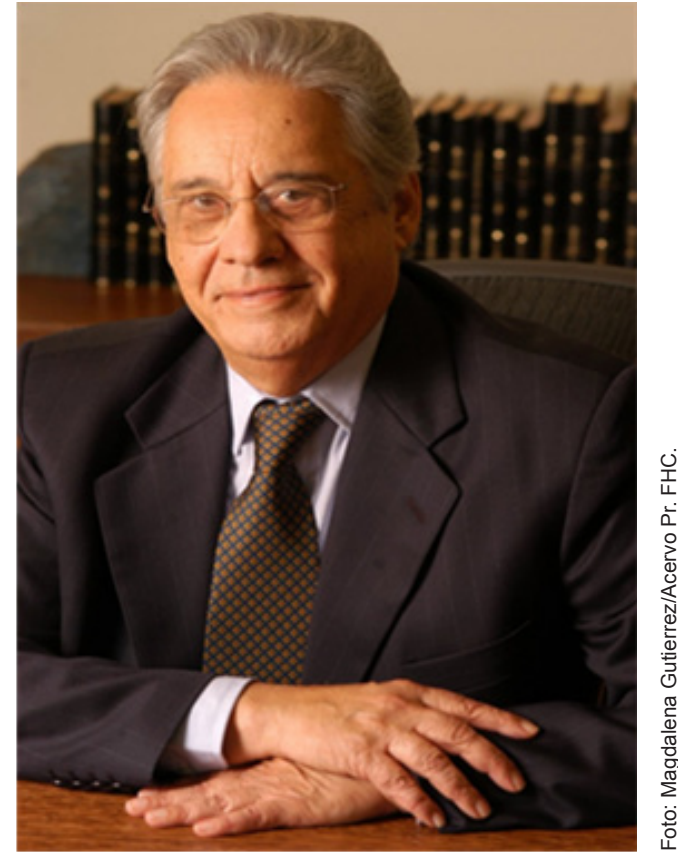

pelo Centro John W. Kluge da Biblioteca do Congresso dos Estados Unidos.

Publicou várias obras, dentre elas: Dependência e desenvolvimento na América Latina, com Enzo Faletto (1969, reeditado em 2004); Capitalismo e escravidão no Brasil meridional: o negro na sociedade escravocrata do Rio Grande do Sul (1962, reeditado em 2003); A construção da democracia (1993); O presidente segundo

\footnotetext{
* Doutor em Sociologia Política pela Universidade Federal de Santa Catarina (Florianópolis, SC, Brasil) e Professor no Centro Universitário de Brusque (Santa Terezinha, SC, Brasil). E-mail:<evesociologia@gmail.com>.
} 
o sociólogo, entrevista a Roberto Pompeu (1998); A arte da política: a história que vivi (2006); O mundo em português, um diálogo com Mário Soares (1998); The accidental president of Brazil (2006); A Soma e o Resto (2011); Pensadores que inventaram o Brasil (2013); Xadrez internacional e social-democracia (2010); Cartas a um jovem político: para construir um país melhor (2006); O Improvável Presidente do Brasil (2013); Pensadores que inventaram o Brasil (2013).

Na carreira política, foi senador, ministro das Relações Exteriores e da Fazenda, e presidente da República, por dois mandatos, no período de 1995-2002. Projetou a criação de um instituto como centro de memória histórica e de debates sobre a democracia e o desenvolvimento. Neste sentido, inaugurou, em maio de 2004, o Instituto Fernando Henrique Cardoso que, em 2010, transformouse em fundação, a Fundação iFHC. No ano de 2013, tomou posse como membro da Academia Brasileira Letras (ABL).

Ao longo de sua vida intelectual sempre teve participação no debate público com sensibilidade para as inquietantes questões sociais e éticas. Nosso objetivo com a entrevista foi conversar com um dos atores sociais que estiveram envolvidos na expansão do mercado de educação superior no Brasil e em Santa Catarina, no período de 1995 a 2002. Nesse período, ocorreram reformas na economia, com a posse do então presidente Fernando Henrique Cardoso, que adotou uma política econômica que assegurasse o desenvolvimento do país de forma competitiva nos mercados nacional e mundial. Nosso entrevistado conhece bem a história político-econômica do Brasil e nesta entrevista - concedida em julho de 2009- apontou aspectos relevantes sobre a educação superior brasileira e mundial.

\section{ENTREVISTA}

- Everaldo: O objetivo da tese, ${ }^{1}$ professor, é descrever a educação superior durante o seu governo, sob a abordagem da sociologia econômica, utilizando autores como Fligstein. Creio que o senhor se lembra que uma das perspectivas do ministério, na sua gestão, era contribuir para a abertura de novas vagas na educação superior, uma vez que o ensino público não atendia à demanda. Por isso, a abertura de universidades privadas que pudessem atender a um número maior de pessoas afastadas dos bancos universitários.

Fernando Henrique CARdoso: $E$, tinha-se essa preocupação de ampliação. E, de fato, havia demanda. $\mathrm{Na}$ época, fez-se muita crítica às universidades privadas e, depois, com o ProUni, tudo aquilo que era criticado passou a ser valorizado, especialmente, a questão de o governo pagar as vagas para escolas privadas. Percebeu-se que era necessário expandir rapidamente.

- Realmente, as instituições públicas não atendiam à demanda.

Talvez não tenham [as universidades públicas] sequer a flexibilidade para poder acompanhar $o$ tipo de oferta que hoje existe. A demanda que hoje existe. A universidade pública é mais rígida nos seus critérios, nos seus currículos.

Pode-se dizer que é mais burocrática?

- Mais burocrática. E, talvez, de melhor qualidade, com melhores níveis de pesquisa também. Houve sempre comentários que as universidades privadas não fazem pesquisa. Mas isso vai mudar. Como elas estão crescendo, acabaram fazendo mais pesquisa. A tendência é ter mais pesquisa nas universidades privadas, nas empresas e expandir a relação empresauniversidade.

Parece que esta é a tendência nos EUA...

$\square$ Nos EUA é muito grande essa relação. A universidade pública no Brasil ficou um "buckler". Defende-se, ela tem medo de ser computada pelo governo e de ser comprada pela empresa. Então se fecha. Há tentativas de abertura porque aumentou a competição. Com o mercado fechado, as universidades privadas não crescem.

- Inclusive, ouvia-se que essa era uma instrução da UNESCO, do Banco Mundial, FMI...

- A Bolsa Família também foi instrução do Banco Mundial! Esse tipo de comentário é preconceituoso porque se a instrução tem validade adotamos, não tendo, descartamos. Isso mostra uma visão provinciana: achar que "o que vem de fora, é imposto pelo Banco Mundial”, como se o Brasil fosse um país que não tivesse capacidade própria de dizer o quer e o que não quer, de adaptar-se.

Lembro-me que havia o receio de que as instituições estrangeiras comprassem o capital ou parte das ações de instituições privadas de ensino superior. Como se faria isso?

Na verdade, já há um movimento neste sentido. No entanto, há certos riscos, indiscutivelmente, mas isso depende um pouco da força que tem o setor nacional e cultural. Em geral, quem compra uma universidade não está interessado no conteúdo, mas no lucro. Se você tiver força própria para gerar conteúdo melhor. Também não quer dizer que você possa formar um sistema educacional com base em empresas, em universidades estrangeiras. Isso não funcionaria. $E$ necessário ter uma universidade brasileira. E nós temos! 
- Existe uma lei que estabelece uma porcentagem de cotas para que instituições privadas comprem...

$\square$ Também há uma lei que estabelece essa porcentagem para as rádios, a televisão, mas tudo com limites préestabelecidos. A tendência, hoje, por exemplo, é que as grandes universidades americanas se globalizem. A universidade de Harvard, por exemplo, tem um escritório em São Paulo, tem um escritório no Chile e já decidiu que, futuramente, um aluno de graduação de Harvard terá que passar um ano fora dos EUA para ter um estudo mais global. O nome "universidade", originariamente, era isso. Não era uma coisa com visão de nação, era a visão do saber, que era universal. Visto universalmente. Depois, com os séculos, o Estado-nação se fortaleceu. Hoje, nós estamos num momento em que, por causa da globalização, o Estado-nação tem outras instituições que não são nacionais, são globais. Ainda não há uma universidade assim, mas algumas nos EUA começam a se mover na direção da globalização. Também não saberia dizer que benefícios isso trará. Não saberia dizer se é saudável. Acho que é complicado quando a universidade cresce muito. Mas, mesmo no início, qual o movimento que existe hoje? É a interconexão. Por causa da internet, você hoje não tem saber que não seja conectado. Precisamos nos abrir, não sermos provincianos. Aliás, eu acho que o risco que os americanos correm é que eles também são provincianos. Atualmente, como são muito fortes, eles se bastam. E, às vezes, sabem pouco do contexto de fora. Por isso, as universidades americanas estão agora querendo criar redes. Para não se isolarem.

- O senhor acredita que deveria haver uma maior regulação no ensino superior para a abertura, para o fechamento de instituições?

$\square$ Eu acredito que o importante é haver a avaliação. Foi muito dificil implantar porque ninguém gosta de avaliação. É difícil, mas é necessário. O governo atual mudou o modo de avaliar, mas não mudou a ideia de avaliar. Havia uma reação contra a ideia no passado, uma visão que é corporativa. No passado, por exemplo, era assim: eu ainda tenho o título, por sorte não existe mais, sou professor catedrático. Fui o último ou penúltimo da USP com esse título de catedrático. Porque significava o seguinte: na disciplina de sociologia havia duas cátedras. Enquanto o catedrático estivesse ativo, até 70 anos, ninguém mais assumia a disciplina. Quando se mudou de cátedra para titularidade, houve uma abertura. Pode-se ter vários titulares de sociologia, isso aumenta a competição. Quando o sistema era fechado, o catedrático mandava até morrer ou fazer 70 anos. Hoje, isso é atrasado. Você precisa ter mais abertura, mais competição. Essa ideia de competição, inclusive, fomos nós que introduzimos, forçosamente, durante o meu governo. É preciso fazer prova, ninguém tem que saber só porque tem o título. É preciso avaliar o professor, avaliar o aluno, avaliar a escola. Começamos avaliando as escolas, nem tanto o aluno, mas a escola, para indicar às pessoas se a escola é boa ou ruim. Embora o governo atual tenha modificado o sistema, não acabou com a ideia. Quando se introduz uma coisa desse tipo e se enraiza, fica dificil mudar. Outra coisa que tentamos fazer e que foi muito difícil foi estabelecer certa relação entre o salário e o mérito. Aqui as pessoas não gostam disso. Elas gostam de status.

- É o poder simbólico de que fala Bourdieu.

$\square$ Ninguém quer saber de mérito. Claro, todo mundo deve ganhar bem, um salário decente para todos, mas o plus depende do desempenho. Na universidade americana não há um salário, eu sou professor na Inglaterra, esse ano fui "professor" da Universidade de Brown. Bom, o meu salário não tem nada a ver com o salário dos outros. Cada um tem o seu salário. Isso depende de uma competição. Eu fui para Brown porque Harvard me fez uma oferta e a Brown cobriu. Dobrou a oferta de Harvard. Bom, isso não é brasileiro! Aqui não se chega a esse ponto. Não condiz com os nossos costumes. Mas um adicional por mérito, eu creio que pode haver. Publicou mais, fez mais pesquisa ou o desempenho foi melhor, então, deve ganhar mais. Isso não é aceito. Nós tentamos, o Paulo Renato fez uma modificação, introduzindo o aumento por mérito. Foi difícil. Estão fazendo isso em São Paulo, novamente, com a Maria Helena Guimarães de Castro, mas isso se relaciona com a mudança do espirito. O problema do Brasil é: como se sai de uma sociedade que era patrimonialista, ainda é, que é corporativa, para uma sociedade meritocrática, que tenha base na competição? Esse é o nosso desafio. Basta ver os escândalos do senado agora. Aquilo tudo é corporativismo, é patrimonialismo. O presidente da república diz: "não, está certo, é assim mesmo". Ele também pensa assim, de modo tradicional, não pensa essas matérias de modo moderno.

- Se não me engano, na Inglaterra, o Tony Blair começou a fazer essas modificações. Ouvi uma palestra de um professor, aqui no Brasil. Ele justamente estava tão acomodado que começou a criticar a atitude do ministro inglês. Refletindo sobre essas questões, o senhor não acha interessante que se crie uma agência reguladora?

Eu não sei, eu preciso pensar se seria... talvez.

- Mas agências como...

․ Como a Anel, Anatel? Agência reguladora é uma forma boa porque regula o mercado. Ele não fica totalmente indefinido. Regula em que sentido? Assegura duas coisas: as condições do investimento, não vai mudar 
a regra do jogo no meio, e o desempenho, o output, o que está oferecendo depende do consumidor e depende do investidor, A agência reguladora é para isso. Ela deve ser sem contingenciamento partidário, político. Para que possa evitar que a ingerência politica venha a alterar as regras do jogo.

- Se, hoje, o senhor fosse novamente presidente da república adotaria um modelo expansionista? Tem ideia de que modelo seria?

$\square \quad$ Uma vez o presidente Itamar Franco, quando estava na transição, quando ia ser presidente, tinha me perguntado se eu aceitaria ser ministro do exterior. Eu era colega dele no senado. Eu disse "está bem". Depois, perguntava sempre para ele: "Quem você vai colocar na educação? quem você vai colocar na educação?" Ele me disse: "Henrique, você quer ser o novo ministro da educação?" Eu disse: "Não, eu quero saber se você vai colocar um clientelista ou não.Eu não quero ser porque eu não sou educador". Eu sou pesquisador, professor. Educador é outra coisa. Eu não sou educador. Eu não sou especializado nessas questões de ensino. Tenho uma experiência, dei aula aqui, em vários lugares do mundo, mas sempre preocupado porque eu estava ali ensinando, pesquisando, não para o sistema educacional. Eu não sei o que eu faria. Acho que precisa avançar mais na democratização, na oferta. É preciso ter requisitos de competição mais fortes, é preciso ter um sistema mais forte de meritocracia, ganha mais quem trabalha mais, sabe mais. Não se pode pensar a universidade como um sistema de igualdade, porque não é. Não é porque uns são melhores que os outros. Se igualar irá mal. Deve-se igualar outras coisas: a renda, direitos e cidadania, isso tem que ser igual. O acesso à saúde, tudo bem. Agora a produção intelectual, é igualar os pintores. Como? Ou músicos. Uns são melhores do que os outros. Há pessoas que têm mais talento, outras porque se esforçaram mais, há gente que tem as duas coisas: talento e esforço. Enfim, a universidade é isso, tem que ser um local onde você valorize os que mais sabem, os que mais produzem. Mas não pode ser medido pela média porque, neste caso, irá mal.

- E, nesse sentindo, houve, em sua gestão, o objetivo de privatizar as universidades públicas?

Isso é insensato! Universidade pública dá um prejuízo enorme. Não é privatizável. Enem eu acho que deveria ser privatizada. É uma contradição do propósito. Você nunca vai ter lucro na USP. A USP é caríssima. E tem que ser! O estado tem que participar disso. Eu sou totalmente favorável à escola pública, principalmente para o ensino fundamental. Não acho que deva ser privada. Tem que ser pública. Pois dá uma base de igualdade, sem invenção ideológica.
- Aproveitando o tema, lembro que o orçamento da educação era algo em torno de onze bilhões de reais. E desses onze bilhões, oito bilhões, praticamente, eram destinados às universidades públicas.

ISSO.

O resto era dividido entre ensino fundamental e médio. Realmente, a universidade federal custa muito caro. É astronômico o valor e o volume que nós temos lá. Não há nenhum tipo de política de longo prazo para inverter essa situação?

Isso sim. Havia o seguinte. Primeiro, a questão é: todos têm acesso, mas a qualidade é baixa e o número de horas que permanecem na escola é pequeno. Para que o país seja mais competente e mais democrático, precisa reforçar o ensino fundamental, primário e secundário. Nenhuma nação moderna dispensa a universidade, a universidade e a pesquisa. É muito importante. Sempre pensei que a ativação da universidade deveria vir pela pesquisa, Fapesp, CNPq, que aliás cumprem esse papel. É a Fapesp que sustenta realmente a pesquisa na universidade. Nós ampliamos a participação. No entanto, há muito desperdício na universidade pública. $O$ aluno é muito caro, não só porque a universidade é cara, mas porque o dinheiro é mal gasto. A burocracia é grande, a carga de trabalho nem sempre é bem distribuida, cobrase pouco os resultados, então, há que se repensar, a longo prazo, se o dinheiro está sendo bem gasto. Eu não acho que a questão no Brasil seja quantidade de dinheiro disponível, mas o que se faz com o dinheiro. Hoje, se olharmos o gasto social do Brasil para o tipo de produto que se tem não é baixo. O resultado é que é baixo. Há muito desperdício, muita burocracia, pouco esforço no sentido de aumentar a eficiência. A universidade se expande sem muita regra pública, quer dizer, sem muito controle. Não creio que privatizá-la resolva o problema. Mesmo porque quem paga não é diretamente o estudante. Quem paga são as fundações, é a prefeitura. Na Inglaterra, assim como nos EUA, também é dessa forma. Segundo, mesmo somando tudo não dá pra manter a universidade. A universidade é cara. A universidade pública para ter boa qualidade, para ter pesquisa precisa de contribuições, de pagamentos. Sigo defendendo que a melhor maneira seja o aumento do imposto de renda para as famílias que têm seus filhos em escola pública e uma renda acima da média. Ou seja, não se cobraria diretamente, mas indiretamente, de quem tem renda. Sempre defendi isso, mas nunca houve oportunidade para implementar um sistema assim. Há muita resistência. O interessante é que a resistência é justamente de quem pode pagar pelo ensino. Vale ressaltar que deveríamos controlar com maior eficiência os gastos e estabelecer certo tipo indireto de cobrança da universidade pública. 
- Fala-se muito que a educação é um bem comercializável, uma espécie de mercadoria. O senhor poderia apresentar-nos seu ponto de vista sobre isso?

$\square$ A educação não pode ser considerada um bem privado. Como disse anteriormente, ela deve ser um bem público. A base da educação precisa ser pública. Agora, não se pode negar que há escola primária paga, que há escola secundária paga, universidade paga, nesse caso, é um bem comercial. Não há o que fazer. Para essa situação se faz necessária uma regulação comercial. Não há outra forma. "Toda a educação deve ser paga?" Não! É fundamental que o estado mantenha a educação. Isso significa que o estado deve pagar tudo que o privado não pode pagar? Não. Porque isso é um engano, o privado pode pagar, seja por si mesmo (por ser autossustentável), seja porque entidades, como congregações religiosas, mantêm a instituição de ensino. Neste último caso, não é com o objetivo de lucro, seus objetivos são ideológicos, culturais. Em situações desta proporção, há necessidade de controle. Cria-se, portanto, uma agência reguladora. Porém é necessário que se esclareça que a parte maior da educação é responsabilidade do governo, do estado. Mesmo nos EUA, o básico da educação fundamental é pública, não é privada. Há várias universidades públicas nos EUA, as maiores são públicas. A Universidade da Califórnia em Berkeley é pública, por exemplo.

E quanto à pesquisa no Brasil?

Ela não é feita na proporção adequada.

A legislação atrapalha ou não estimula?

A legislação não estimula. A legislação americana, por exemplo, incentiva. Nos Estados Unidos, podese fazer uma pré-herança, ou seja, pode-se dispor em vida de uma parte da herança. Lá há imposto de herança, aqui não. No nosso país não há controle para isso. O imposto de herança no Brasil é estadual, nem todos os estados cobram e quando cobram é 3 ou 4 por cento do valor do espólio. Lá não é assim. Na Europa, nos Estados Unidos, paga-se muito de imposto de herança. Uma parte do que se iria deixar de herança pode, em vida, ser atribuída a alguém. Por isso, há tanta faculdade com nome de pessoas porque ao invés de dar a herança para o estado, o indivíduo, em vida, doa para uma universidade. Aqui não há nada semelhante. Mudou um pouco, é claro! Mas, antes que mudássemos a lei, era necessário pagar 25 por cento sobre o valor de uma doação. A situação mudou porque o Mindlin, que era um colecionador famoso, doou, ou melhor, ia doar um acervo para a Universidade de São Paulo, mas não tinha dinheiro para pagar o imposto. A biblioteca dele vale milhões de dólares, $25 \%$ de milhões de dólares é difícil de pagar. É descabido que se cobre imposto pela doação. E há mais, caso se queira doar algo não há nenhum desconto, nenhum tipo de incentivo. O único instrumento de desconto é a lei Rouanet para projetos especificos.

- Outra questão: Como se sabe, a OAB está incentivando o fechamento de vários cursos de direito e essa está se tornando uma espécie de tendência entre as classes profissionais. Em sua forma de ver, esse fenômeno está ocorrendo em virtude da expansão ou por causa da falta de controle?

Por falta de controle. Insisto: tem-se que exigir qualidade. Ofato de se permitir que abram instituições de ensino superior não quer dizer que se pode abrir qualquer coisa. Tem-se que exigir qualidade. Nós não aumentamos a exigência de qualificação, mestrado, doutorado? E essa exigência foi importante. É preciso incentivar a qualificação do profissional, tomando o cuidado de não criar indústrias de mestrado, indústrias de doutorado, feitos às pressas só para obter-se titulação. Isso tudo precisa de órgãos reguladores. O mundo contemporâneo exige um misto de liberdade e controle. Vemos a crise financeira. Há que se ter uma regra consensual e mecanismos que assegurem que não seja impositiva, não seja arbitrária, não seja discricionária, não seja ideológica, não seja política, etc.

- O senhor não vê como corporativista esta posição da OAB? Continuará, sob seu ponto de vista, a existir essa pressão da Ordem?

$\square$ Pode ser. É preciso verificar a qualidade das escolas. Sempre há um pouco de corporativismo. Isso no Brasil é inevitável. Na medicina, por exemplo, havia uma autodefesa de mercado muito forte. Lembro-me da época em que era do conselho universitário da USP, há muitos anos, de 1950 até 1964. Lá havia uma briga porque não queriam que aumentássemos o número de vagas para o curso. Era o chamado numerusclausus que se usava na Alemanha nazista. Não podia passar de 60 novos alunos.

- Sua colocação me faz lembrar que há muita reclamação dos alunos sobre o número de estudantes por sala de aula. Nos Estados Unidos, em outros países, sempre houve um grande número de alunos em sala, em condições físicas piores do que as que oferecemos. Isso também é uma otimização de recursos.

$\square$ Aqui não há utilização de recursos, aqui há recursos desperdiçados. Com muita dificuldade se aumentou o número de vagas no curso de Medicina, mas foi um aumento a conta gotas. Hoje há uma tendência em afirmar que a qualidade do ensino decaiu. Veja: quando ingressei como estudante na USP, em 1948 ou 1949, a maioria de meus professores era de estrangeiros. No segundo ano da faculdade as aulas eram em francês porque todos os professores daquele período eram franceses. O número de alunos, como 
se pode imaginar, era pequeno. Somente uma elite tinha um nivel elevado a ponto de ter aulas em francês. A instituição importava seus profissionais da Sorbonne e de outras universidades de destaque da Europa. O nivel era elevado? Tinha que ser! No entanto, quantos podiam ter acesso a uma formação assim? Não se pode negar que esse tipo de ensino formou grandes intelectuais, que muito fizeram por nosso pais. O problema é que, hoje, não podemos mais adotar essa politica. É necessário ampliar o acesso ao ensino e, provavelmente acontecerá aqui o mesmo fenômeno que ocorreu nos EUA. Lá se faz a faculdade, o "College" como é chamado. Mas essa formação não qualifica para muita coisa. Melhora o nivel, mas não qualifica muito. Nos Estados Unidos, entra-se na faculdade, escolhe-se a profissão, há uma flexibilização do currículo que permite que o aluno estude, por exemplo, física, poesia grega e música. Somente depois, em cursos de especialização é que ocorre a qualificação do profissional. É no mestrado que ocorre a verdadeira seleção profissional. Por mais que digam que baixou o nível, é melhor tê-lo baixo do que não tê-lo. Alguns céticos afirmam: mas a pessoa vai à faculdade para depois ser chofer de táxi. É melhor ser chofer de táxi tendo mais cultura, podendo usufruir dos bens culturais do que não ter qualificação nenhuma. Somente desse modo se aumentará o nível educacional comparável ao da elite. Não há dúvidas de que no sistema que mencionei antes, as pessoas passavam de 4 a 5 anos convivendo com profissionais muito competentes, tendo estímulos diretos para uma formação de altíssimo nível. No entanto, no contexto mundial atual, isso é insuficiente. O mundo contemporâneo exige maior abertura, com isso, o nivel educacional diminui, mas depois aumenta. As universidades americanas, por exemplo, muitas são ruins. Remetemo-nos sempre às famosas. E as outras? Há milhares. Como já mencionei, leciono lá. Só na região de Boston e Providence, são 60 universidades. Uma é Harvard, outra é o MIT, outra é Brown, outra é a Massachusetts University, mas são 60. Outro dia fui convidado a fazer uma conferência em uma universidade da qual nunca tinha ouvido falar, aliás não me lembro sequer o nome. Ficava a aproximadamente uns 5 ou $6 \mathrm{~km}$ de onde eu trabalho. Cheguei e tive uma grata surpresa, o campus era todo "wireless". A biblioteca era fantástica. Eles tinham uma miniatura de "Wall Street" para que os alunos aprendessem o funcionamento da bolsa. E eu nunca tinha ouvido falar naquela universidade. Aqui já começou esse movimento, há uma quantidade de universidades, de faculdades que já estão em processo de remodelação, de melhoramento. Não sou pessimista quanto a isso. É preciso dar mais acesso, democratizar e criar um sistema de méritos. Criar um sistema de avaliação para que os pais saibam quanto vão pagar e o que vão receber em troca no que diz respeito ao ensino formal de seus filhos.

- Se me permite, professor, gostaria de saber: Como se sente o homem Fernando Henrique, quinze anos após a grande mudança ou início do grande avanço do Brasil em termos econômicos, já que sabemos que isso foi preconizado, iniciado pela sua administração.

Fui a Brasília, esses dias, porque havia uma sessão no Senado em comemoração ao Real. Eu me senti bem, porque todos, até o pessoal do PT estava lá. É bom ver que o que começamos está funcionando e que as pessoas já reconhecem o que foi feito. Depois desses quinze anos eu não faria a mesma coisa. Se voltasse no tempo, corrigiria onde errei, mas se faz o que é possivel em certos momentos. Ser engenheiro de obra feita é fácil. Nunca tive obsessão pelo poder, de ficar no poder. Quando sai, disse que não voltaria. Não que não tenha gostado. Não é isso! Mas cada um tem que saber o seu momento não só na história, mas na vida.

- Mas houve comentários de que o senhor trabalharia no BIRD.

$\square \quad V o c e ̂$ acha que vou querer ser chefe de uma burocracia como o BIRD. Não quero. Já tenho muita coisa para fazer sem que sejam posições formais, nem sei qual é a minha agenda de tanta coisa que eu tenho para fazer aqui e fora.

- Para finalizar: Quando o senhor assumiu houve a expectativa de que um sociólogo poderia resolver quase todos os problemas sociais do país. O que tem a dizer sobre isso?

$\square$ Quando se está no governo são tantas coisas para resolver, depende não só de você, mas dos outros, da situação, dos instrumentos, da política, não é fácil. Introduzir modificações é sempre difícil. $O$ Mercadante chegou a afirmar que nós tivemos 8 anos de Real e eles só seis anos e meio. Minha resposta foi: "Vocês têm seis e meio no trilho que nós fizemos, depois do trilho pronto podem andar o tempo que quiserem".

\section{NotA}

1 Tese de Doutorado em Sociologia Política (2010) apresentada ao Programa de Pós-Graduação em Sociologia Política, do Centro de Filosofia e Ciências Humanas da Universidade Federal de Santa Catarina - UFSC.

Entrevista recebida em novembro 2013.

Aprovada em janeiro 2014. 